\title{
Educational demographics of orthopaedic surgery department chairs
}

\author{
Sean C. Clark, MS ${ }^{1}{ }^{\text {a }}$, Cadence Miskimin, MS ${ }^{2}$, Mary K. Mulcahey, MD² \\ 1 Tulane University School of Medicine, ${ }^{2}$ Department of Orthopaedic Surgery, Tulane University School of Medicine \\ Keywords: fellowship, residency, medical school, orthopaedic surgery, department chair \\ https://doi.org/10.52965/001c.31917
}

\section{Orthopedic Reviews}

Vol. 14, Issue 1, 2022

\section{Background}

Becoming chair of an academic clinical department is a tremendous achievement that takes many years of experience and clinical excellence.

\section{Objective}

The purpose of this study was to determine the educational demographics of current orthopaedic surgery department chairs in the United States.

\section{Methods}

A complete list of orthopaedic surgery residency programs was obtained from the Accreditation Council for Graduate Medical Education (ACGME) 2019-2020 list of residency programs. Department chairs were identified through an online search. Educational data, including where the department chair went to medical school, residency, fellowship, and type of fellowship completed were obtained.

\section{Results}

A total of 145 orthopaedic department chairs were identified. The most attended medical schools by department chairs were Baylor (6 of 145, 4.1\%) and Northwestern (6 of 145 , $4.1 \%)$. The University of Rochester was the most common orthopaedic residency attended (9 of 145, 6.2\%) and Harvard was the most common orthopaedic clinical fellowship (20 of $133,15.0 \%)$. On average, it took 17.9 years from completion of clinical training to being named department chair.

\section{Conclusion}

This study provides insight into the academic credentials, length of clinical experience, and research productivity of current orthopaedic surgery department chairs. Certain training programs may be more likely to produce department chairs and, in general, an orthopaedic surgeon is more likely to become chair at an institution where he/she previously trained. Finally, research productivity is clearly an important factor in becoming chair, as most chairs have high h-indices and a consistent track record of research excellence.

\section{INTRODUCTION}

Becoming chair of an academic clinical department is a tremendous achievement that takes many years of experi- ence and clinical excellence. The chair has numerous responsibilities including managing the faculty, residents, and staff while maintaining clinical duties, research, teaching residents and fellows, and attending national confer-

\footnotetext{
a Corresponding author: Sean C. Clark, MS

1430 Tulane Avenue New Orleans, LA 70112 Phone: $610-731-1300$ Email: sclark19@tulane.edu
} 
ences. ${ }^{1,2}$ Although there is a lack of objective data regarding physicians' qualifications for obtaining leadership positions, previous studies have provided insight into the experience necessary to become an academic department chair.

In 2007, Mets et al. reported on the characteristics, accomplishments, and motivations of anesthesiology department chairs. ${ }^{3}$ When asked what advice current anesthesiology chairs would give to assistant professors who aspire to become chair, the highest rated advice was to become a division director with clinical, administrative, education, and research responsibilities. Additionally, 24\% of chairs reported that being vice chair was the most helpful experience for their current position and $68 \%$ of the chairs decided early on in their career, either as a resident, fellow, or assistant professor, that they wanted to be chair in the future. ${ }^{3}$ Another study by Dotan et al. surveyed academic ophthalmology department chairs in the United States to understand their characteristics, accomplishments, and past experiences. ${ }^{4}$ Of their previous experiences, ophthalmology chairs regarded being head of service as most significant and relevant to their current role. The most important advice for aspiring chairs was to take on multiple responsibilities and become a clinician, researcher, and educator. Finally, in contrast to Mets et al., respondents decided to become department chairs later in their career as either full or associate professors. ${ }^{4}$ Thus, being able to manage numerous responsibilities within the department has been shown to be associated with successfully being appointed as chair.

Although these studies have examined the characteristics of academic department chairs, few have focused specifically on the characteristics of orthopaedic surgery department chairs. The purpose of this study was to determine the educational demographics of current orthopaedic surgery department chairs in the United States.

\section{MATERIALS AND METHODS}

\section{ETHICAL CONSIDERATIONS}

The authors complied with all ethical standards as this study did not require human interaction.

The websites for all 202 ACGME accredited orthopaedic surgery residency programs in the United States were searched in April 2020 to identify the department chair for each program. Military programs (8 of 202, 4.0\%) and programs that traditionally accept osteopathic medical students (41 of 202, 20.3\%) were excluded. Other programs that may not have had a chair due to recent resignation, retirement, or death ( 8 of $202,4.0 \%$ ) were also excluded. Institutional websites, curricula vitae (CVs), and news articles were used to gather information on the remaining 145 identified chairs. Educational data, including where the chair went to medical school, residency, fellowship, and type of clinical fellowship completed were obtained. Additional information including gender, time from completion of a clinical fellowship or residency to being named chair, time at an institution before being appointed chair at the same institution, amount of time as current chair, and h-in- dex were obtained. H-index, which measures both the productivity and impact of the author's research, was obtained through the Scopus database. ${ }^{5}$

\section{RESULTS}

A total of 145 orthopaedic surgery department chairs were identified, 141 of whom were male (97.2\%) and 4 of whom were female (2.8\%). All had a Doctor of Medicine (MD) degree (143 of $145,98.6 \%)$ except $1(0.7 \%)$ chair having a Doctor of Osteopathic Medicine (DO) degree, and 1 (0.7\%) having a Bachelor of Medicine, Bachelor of Surgery (MB $\mathrm{ChB}$ ), and Master of Medicine (MMed) degrees. Seven chairs (4.8\%) had Master of Business Administration (MBA) degrees and 4 (2.8\%) had Doctor of Philosophy degrees (PhD). Out of the past 10 Presidents of the American Academy of Orthopaedic Surgeons (AAOS), 3 (30\%) are current department chairs.

The institutions where department chairs completed medical school or residency were identified in all cases, while clinical fellowship was identified for 133 of 145 (91.7\%) chairs and type of clinical fellowship was identified for 131 of 145 (90.3\%). The most commonly attended medical schools by department chairs were Baylor University College of Medicine ( 6 of 145, 4.1\%), Northwestern University Feinberg School of Medicine (6 of 145, 4.1\%), Georgetown University School of Medicine (5 of 145, 3.4\%), Sidney Kimmel Medical College at Thomas Jefferson University (5 of $145,3.4 \%$ ), and Duke University School of Medicine (4 of 145, 2.8\%) (Figure 1).

The most common residency training programs for department chairs were the University of Rochester (9 of 145, 6.2\%), Hospital for Special Surgery/Cornell Medical Center (7 of $145,4.8 \%$ ), Case Western Reserve University/University Hospitals Cleveland Medical Center (6 of 145, 4.1\%), Duke University Hospital (5 of 145, 3.4\%), and University of Pennsylvania Health System (4 of 145, 2.8\%) (Figure 2).

The most common fellowship programs attended were Massachusetts General Hospital/Brigham and Women's Hospital/Harvard Medical School (20 of 133, 15.0\%), Hospital for Special Surgery/Cornell Medical Center (11 of 133, 8.3\%), Cleveland Clinic Foundation Program (6 of 133, 4.5\%), and University of Pennsylvania Health System (6 of 133, 4.5\%) (Figure 3). The most popular types of clinical fellowships completed by department chairs were sports medicine (30 of $131,22.9 \%$ ), trauma (21 of $131,16.0 \%$ ), spine (20 of 131, 15.3\%), hand (16 of 131, 12.2\%), and oncology (14 of 131, 10.7\%) (Figure 4).

The average time from completion of training, whether that be through residency or a clinical fellowship, until being named chair of the department of orthopaedic surgery was 17.9 years (range $7-34$ ). The average time spent at an institution before being appointed chair of the department of orthopaedic surgery at that same institution was 7.7 years (range $0-26$, with 0 meaning the individual came from a different institution). The average length of time chairs have held their current position is 8.3 years (range 1-31). Forty-six of 145 (31.7\%) orthopaedic surgery department chairs completed medical school, residency, or fellowship 


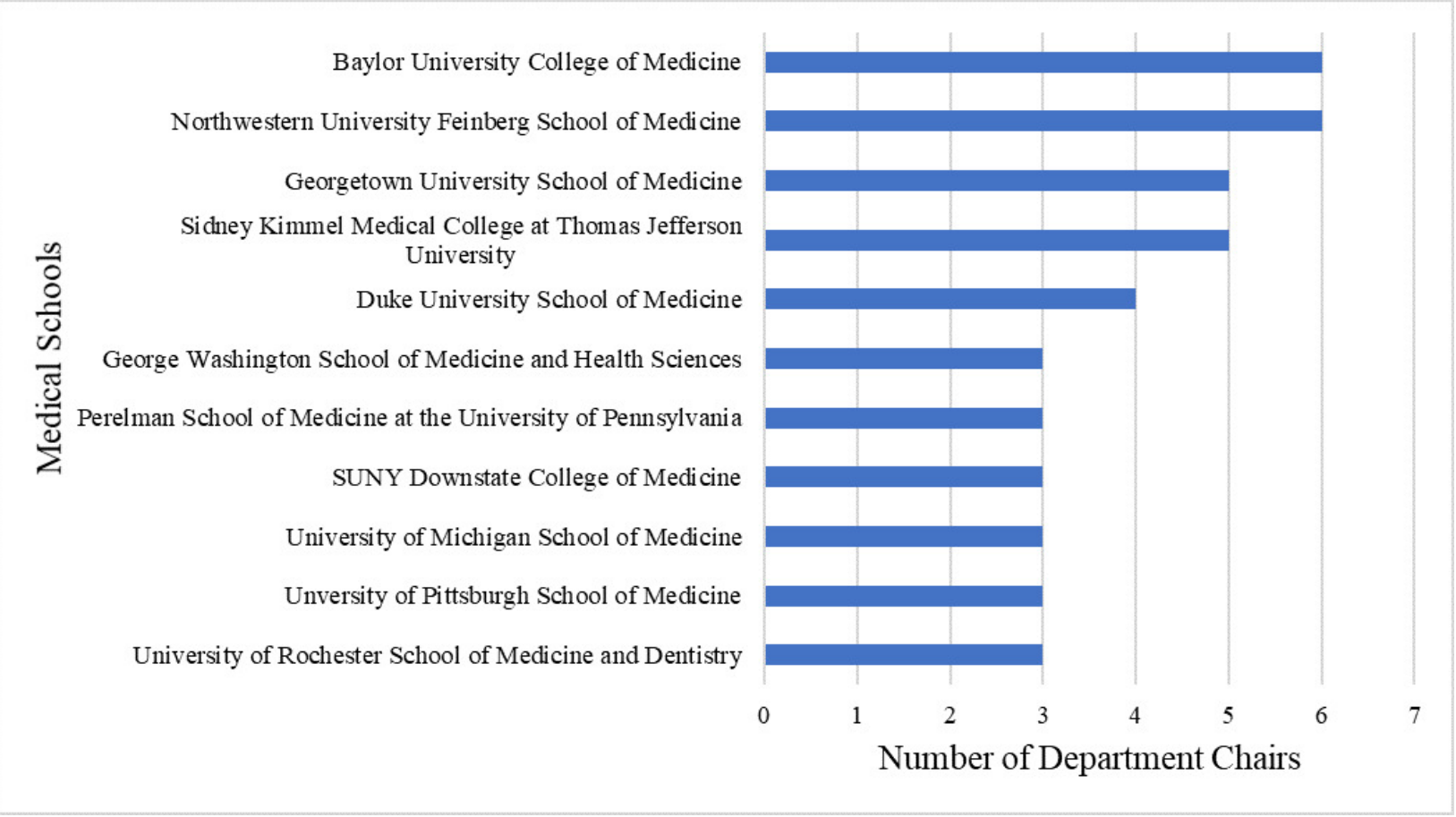

Figure 1. Most attended medical schools by orthopaedic department chairs.

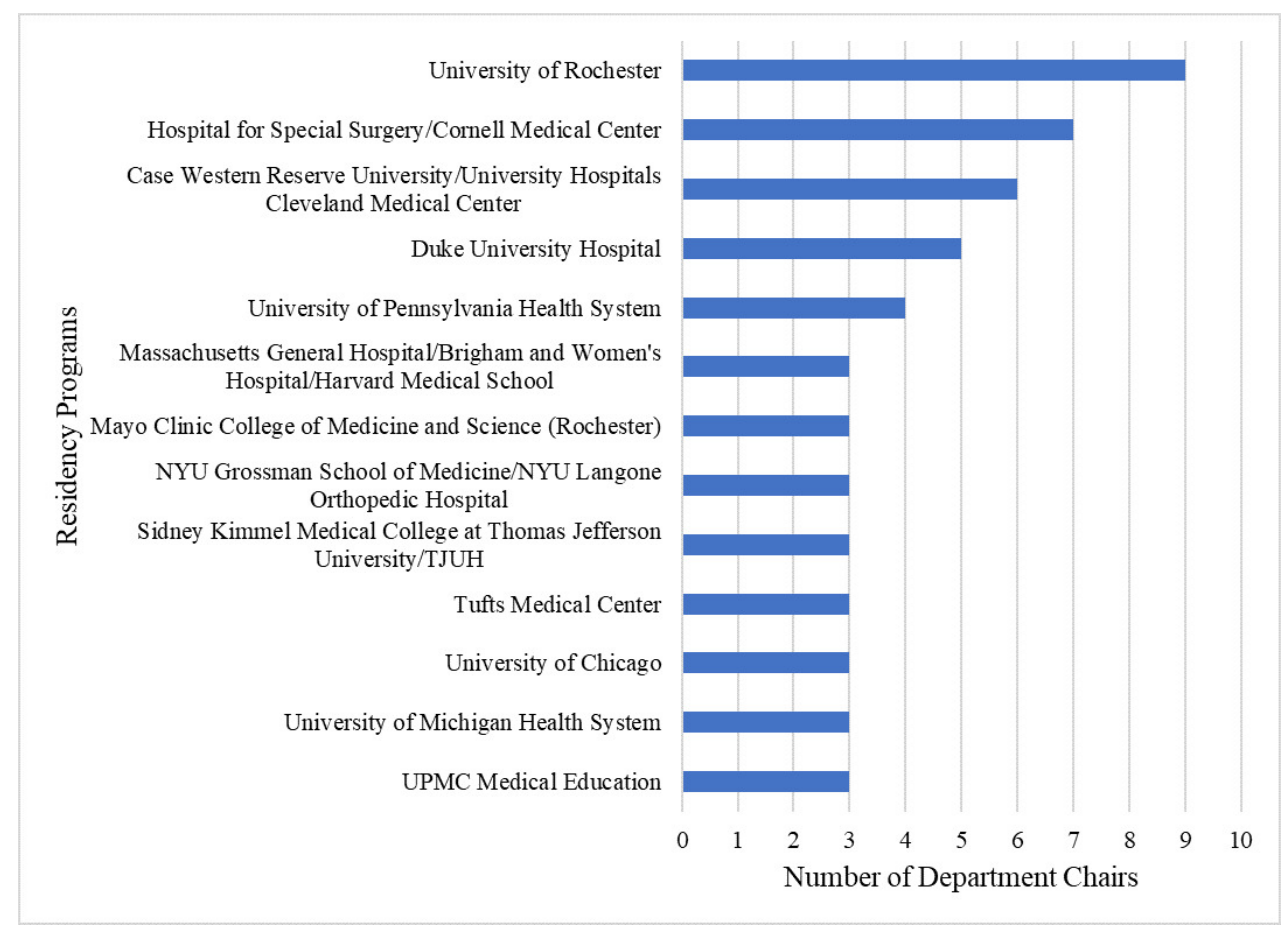

Figure 2. Most attended residency programs by orthopaedic department chairs.

training at the institution where they are now the department head. The average h-index of the current department chairs is 25.8 (range 1-105) (Figure 5).

\section{DISCUSSION}

Many of the current orthopaedic surgery department chairs completed their training at select programs, including Bay- lor University College of Medicine, Northwestern University Feinberg School of Medicine, University of Rochester, and Massachusetts General Hospital/Brigham and Women's Hospital/Harvard Medical School (Figures $\underline{1}-\underline{3}$ ). Completing clinical training at these institutions may prepare an individual for a successful career in academic medicine and thus, make graduates more qualified to assume a position of department chair. In addition, individuals may pursue these programs because they are more interested in acad- 


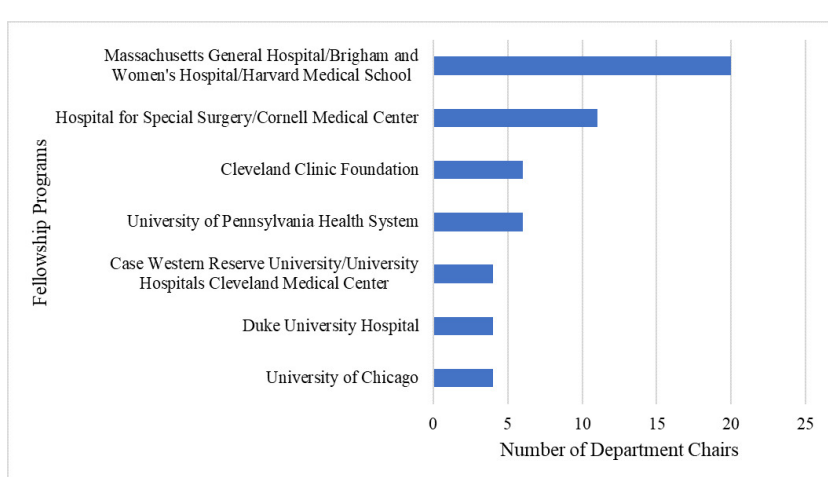

Figure 3. Most attended clinical fellowship programs by orthopaedic department chairs.

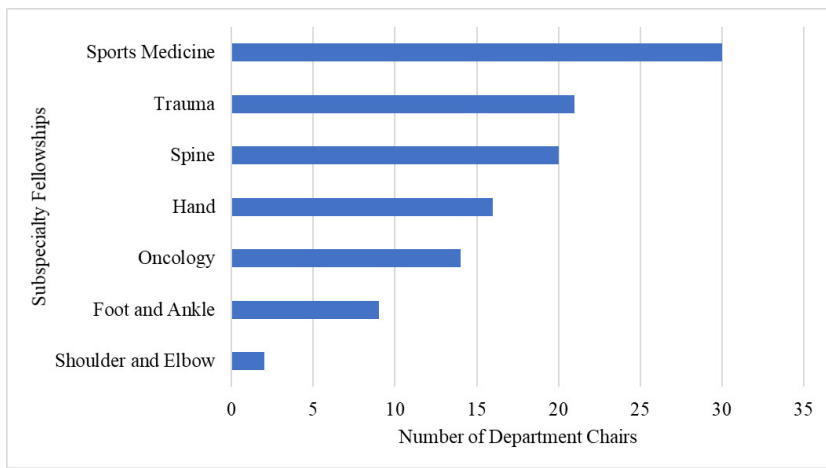

Figure 4. Most common types of clinical fellowships completed by orthopaedic department chairs.

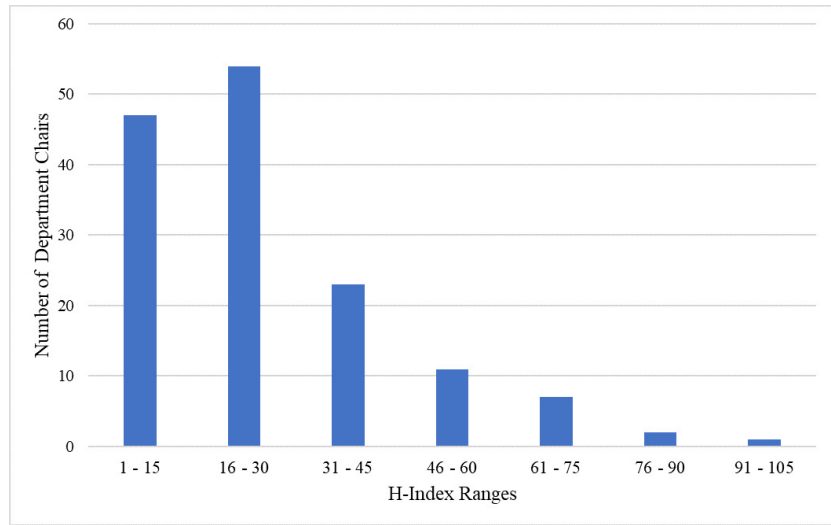

Figure 5. Scopus h-indices of orthopaedic department chairs.

emic medicine rather than private practice. Finally, institutions undergoing a search for a new chair may preferentially hire individuals who have trained at these specific programs, as they are highly ranked and may look favorable on one's CV when applying for a chair position. ${ }^{6}$

In 2020, Donally et al. studied the demographic trends of spine fellowship directors and found a potential correlation between specific residency and fellowship training programs, such as Case Western Reserve University, and their graduates becoming spine fellowship leaders. ${ }^{6}$ Similarly, our study demonstrates that Case Western Reserve University is one of the most attended residency and fellowship programs by current orthopaedic department chairs (Figures $\underline{2}$ and $\underline{3}$ ). In 2011, Campbell et al. studied the factors that may influence neurological surgeons decision to pursue a career in academic medicine. ${ }^{7}$ The authors found that three residency programs were responsible for training over $10 \%$ of all academic neurosurgeons. Thus, where an individual receives training may play a significant role in one's career choice of entering academic medicine and assuming leadership positions.

Networking, especially early on in one's academic career, can foster career development and long-term success. ${ }^{8}$ Nearly $32 \%$ of orthopaedic department chairs completed medical school, residency, or fellowship at the institution where they are presently chair. A similar study by Bi et al. found that orthopaedic department chairs and program directors commonly trained at the same residency program as their current institution. ${ }^{9}$ Additionally, Donally et al. found that $13.6 \%$ of spine fellowship directors are currently practicing at the same institution where they completed residency and $12.6 \%$ are currently practicing at the same institution where they completed fellowship. ${ }^{6}$ In 2009, Adonna et al. surveyed academic plastic surgery department chairs and found that nearly $70 \%$ were promoted from within the department. ${ }^{10}$ Institutions may be inclined to hire candidates internally or with institutional affiliation as creating a national search committee to hire externally can be expensive. Also, internal candidates or previous trainees may be more vested in the institution, less likely to leave for another job, and hold the position for a longer period of time. ${ }^{10}$

Current orthopaedic department chairs have an average h-index of 25.8 , with most above 15 , suggesting that substantial and impactful research in the field of orthopaedic surgery is an important factor for becoming a department chair (Figure 5 ). ${ }^{2}$ Bastian et al. investigated the relationship between h-indices and academic rank for faculty members from 120 academic orthopaedic surgery residency programs in the United States. ${ }^{5}$ A significant relationship was found between h-index and academic rank among orthopaedic surgeons, as associate professors attained higher mean hindex values than assistant professors $(\mathrm{p}<0.0001)$, professors attained higher mean $h$-index values than associate professors $(p<0.0001)$, and chairs attained higher mean $h$-index values than professors $(\mathrm{p}<0.05)$. Specifically, the mean h-indices of assistant professors, associate professors, professors, and chairs were 3.6, 8.4, 15.1, and 17.8, respectively. ${ }^{5}$ Similarly, Cvetanovich et al. studied the academic productivity of 610 sports medicine faculty across 90 orthopaedic sports medicine fellowship programs and found a significant positive correlation between $\mathrm{h}$-index and academic rank $(\mathrm{p}<0.001) .{ }^{11}$ Full professors had a significantly higher $\mathrm{h}$-index compared to associate professors and associate professors had a significantly higher $\mathrm{h}$-index compared to assistant professors ( $\mathrm{p}<0.001)$. Only $4(2.8 \%)$ current orthopaedic department chairs have PhD degrees, which generally provides extensive research training. Regardless, the remaining chairs, without this degree, were 
still highly productive and were likely able to gain research skills throughout their medical training or clinical practice.

\section{LIMITATIONS}

This is a cross-sectional study as data was retrieved at one point in time and findings may differ if this information was followed over several years. Data was obtained through an online search and some websites may have listed incorrect information about the department chairs. Not all details could be obtained for each chair such as where the chair completed fellowship, type of fellowship completed, time since completion of clinical training until being appointed chair, amount of time as chair, and time spent at an institution before being named chair at that same institution. Since some chairs have worked at multiple institutions throughout their career, they may have had multiple $\mathrm{h}$-indices listed on the Scopus website. If these values were integrated, the h-index may be higher for those chairs. The Scopus h-index is also limiting as it is only based on publications from 1996 to the present. ${ }^{12}$ Thus, chairs with research productivity prior to this time may have lower than expected $\mathrm{h}$-index scores. As a result, the average $\mathrm{h}$-index may be underreported.

\section{CONCLUSION}

This study provides insight into the academic credentials, length of clinical experience, and research productivity of current orthopaedic surgery department chairs. Certain training programs may produce department chairs and, in general, an orthopaedic surgeon is more likely to become chair at an institution where he/she previously trained. Finally, research productivity is clearly an important factor in becoming chair, as most chairs have high h-indices and a consistent track record of research excellence.

\section{AUTHOR'S CONTRIBUTIONS}

Sean C. Clark: data collection, data analysis, manuscript preparation

Cadence Miskimin: data analysis, manuscript preparation, manuscript revision

Mary K. Mulcahey: project conception, manuscript preparation, manuscript revision

\section{DISCLOSURES}

All authors have no disclosures.

\section{FURTHER INFORMATION}

This study will be a podium presentation for The Association of Bone and Joint Surgeons 2021 Annual Meeting. This study will be a poster presentation at the American Academy of Orthopaedic Surgeons 2021 Annual Meeting. This study was a poster presentation at the American Orthopaedic Association 2021 Annual Meeting and the Louisiana Orthopaedic Association 2021 Annual Meeting. 


\section{REFERENCES}

1. Salazar DH, Herndon JH, Vail TP, Zuckerman JD, Gelberman RH. The Academic Chair: Achieving Success in a Rapidly Evolving Health-Care Environment: AOA Critical Issues. J Bone Joint Surg Am. 2018;100(20):e133. doi:10.2106/jbjs.17.01056

2. Klein G, Hussain N, Sprague S, Mehlman CT, Dogbey G, Bhandari M. Characteristics of highly successful orthopedic surgeons: a survey of orthopedic chairs and editors. Can J Surg. 2013;56(3):192-198. doi:10.1503/cjs.017511

3. Mets B, Galford JA, Purichia HR. Leadership of United States academic anesthesiology programs 2006: chairperson characteristics and accomplishments. Anesth Analg. 2007;105(5):1338-1345, table of contents. doi:10.121 3/01.ane.0000284666.39224.05

4. Dotan G, Qureshi HM, Saraf SS, Darnley-Fisch DA. Leadership of United States Academic Departments of Ophthalmology: Chairperson Characteristics, Accomplishments, and Personal Insights. Am J Ophthalmol. 2018;186:69-76. doi:10.1016/j.ajo.2017.1 $\underline{0.024}$

5. Bastian S, Ippolito JA, Lopez SA, Eloy JA, Beebe KS. The Use of the h-Index in Academic Orthopaedic Surgery. J Bone Joint Surg Am. 2017;99(4):e14. doi:1 $\underline{0.2106 / \text { ibjs. } 15.01354}$

6. Donnally CJ 3rd, Schiller NC, Butler AJ, et al. Trends in Leadership at Spine Surgery Fellowships. Spine (Phila Pa 1976). 2020;45(10):E594-e599. doi:1 0.1097/brs.0000000000003350
7. Campbell PG, Awe OO, Maltenfort MG, et al. Medical school and residency influence on choice of an academic career and academic productivity among neurosurgery faculty in the United States. Clinical article. J Neurosurg. 2011;115(2):380-386. doi:10.317 1/2011.3.Jns 101176

8. Ansmann L, Flickinger TE, Barello S, et al. Career development for early career academics: benefits of networking and the role of professional societies. Patient Educ Couns. 2014;97(1):132-134. doi:10.1016/ i.pec.2014.06.013

9. Bi AS, Fisher ND, Singh SK, Strauss EJ, Zuckerman JD, Egol KA. The Current State of Orthopaedic Educational Leadership. J Am Acad Orthop Surg. 2021;29(4):167-175. doi:10.5435/jaaos-d-20-00279

10. Addona T, Polcino M, Silver L, Taub PJ. Leadership trends in plastic surgery. Plast Reconstr Surg. 2009;123(2):750-753. doi:10.1097/PRS.0b013e3 18197ed20

11. Cvetanovich GL, Saltzman BM, Chalmers PN, Frank RM, Cole BJ, Bach BR Jr. Research Productivity of Sports Medicine Fellowship Faculty. Orthop J Sports Med. 2016;4(12):2325967116679393. doi:10.11 $\underline{77 / 2325967116679393}$

12. Doja A, Eady K, Horsley T, Bould MD, Victor JC, Sampson M. The h-index in medical education: an analysis of medical education journal editorial boards. BMC Medical Education. 2014;14(1):251. doi:1 0.1186/s12909-014-0251-8 